\title{
O Impacto das Decisões Estratégicas no Desempenho dos Franqueados em Fast-Food: o Papel do Relacionamento Franqueador-Franqueado
}

\author{
Marcos Cohen \\ Jorge Ferreira da Silva
}

\section{RESUMO}

Tendo como motivação o crescente interesse e controvérsia despertados pela prática do franchising no Brasil, este trabalho descreve pesquisa realizada entre franqueados de redes de fast-food de todo o país, que mediu sua percepção das estratégias competitivas praticadas por seus franqueadores e sua satisfação com o relacionamento franqueador-franqueado, visando a identificar o papel desse relacionamento no desempenho médio desses mesmos franqueados. O principal objetivo da pesquisa foi verificar, à luz da teoria de Porter (1980) sobre estratégias competitivas, se a diferença de desempenho médio (medido de maneira qualitativa através da satisfação dos franqueados) entre grupos estratégicos de franqueados da indústria do fast-food poderia ser explicada pela diferença na qualidade do relacionamento franqueador-franqueado percebida por esses mesmos franqueados. Para tanto, procurou-se representar essa qualidade de relacionamento por meio de variáveis observáveis, características do franchising, medidas por uma escala qualitativa de satisfação dos franqueados.

Palavras-chaves: estratégia; desempenho; franquia.

\begin{abstract}
This paper describes a research made among Brazilian fast-food franchisees, measuring their perception about the competitive strategies practiced by their respective franchisors and their assessment of the franchisor-franchisee relationship quality. Based upon Porter's (1980) theory on competitive strategies, it was tested if the difference in the average performance among strategic groups of franchisees could be explained by the difference in the franchisor-franchisee relationship quality as perceived by these franchisees. In order to accomplish that, the relationship quality latent variable was represented by different observable variables present in the franchise system and measured through a qualitative scale of the franchisees' satisfaction.
\end{abstract}

Key words: strategy; performance; franchise. 


\section{Contextualização do Problema}

Um dos temas de negócios mais em evidência no país atualmente é o franchising, ou sistema de franquia. Isso se deve não apenas ao significativo crescimento que esse tipo de empreendimento experimentou nos últimos cinco anos, mas também às controvérsias geradas a respeito dos resultados dessa evolução, sobretudo quanto ao desempenho dos franqueados quando comparado ao de seus franqueadores.

Vários autores citam como principais vantagens da adoção do franchising por empreendedores inexperientes: uso de marca consagrada, apoio operacional do franqueador, menor curva de aprendizado, utilização de método de trabalho já testado e a implantação e treinamento feitos pelo franqueador, que reverteriam em taxa de retorno mais rápida sobre seu investimento e grau de risco bem menor do que se investisse por conta própria. Já para o franqueador as principais vantagens se traduziriam por este elenco: expansão da rede e marca com capital de terceiros, economia de escala para sua produção, manutenção do controle das decisões da rede, maior faturamento sem a necessidade de grandes investimentos ou custos operacionais e receitas mensais certas provenientes de royalties e da venda de produtos ou serviços aos franqueados (Cherto, 1988; Leite, 1991; Mauro, 1994).

No entanto a realidade tem mostrado que o franchising também apresenta problemas. Com as recentes crises econômicas, várias redes vêm enfrentando freqüentes reclamações de seus franqueados, visando à redução de taxas e a uma atitude que reflita mais compromisso com a parceria. Recentes experiências mal sucedidas, tanto de franqueadores quanto de franqueados, têm gerado questionamentos e pesquisas sobre a eficácia do franchising como mecanismo capaz de gerar benefícios, consistentes e mútuos, ao longo do tempo. Proença (1997) menciona que apenas $25 \%$ das 74 empresas franqueadoras pesquisadas por Stenworth em 1984 na Inglaterra foram consideradas bem sucedidas por especialistas em 1994, enquanto 50\% daquelas empresas já não existiam. Nos Estados Unidos, Shane (1996) chegou a resultado semelhante com uma amostra de 138 empresas franqueadoras, para o período de 1983 a 1993. No Brasil, enquanto em 1996 o número de unidades de franquia abertas foi $47 \%$ maior que o de 1994, o número de unidades fechadas aumentou 74\%. Em números absolutos, a cada 8 unidades franqueadas abertas em 1996, uma outra unidade fechava suas portas, enquanto em 1994 esta relação era de 9,3. 
Algumas das reclamações mais freqüentes entre aqueles franqueados insatisfeitos dizem respeito ao apoio inadequado e despreparo administrativo por parte do franqueador, à cobrança de taxas e royalties exorbitantes, à submissão quase total do franqueado às normas ou decisões do franqueador e ao fornecimento de dados irrealistas quanto a capital investido, custos e tempo de retorno do investimento. Já pelo lado dos franqueadores, as queixas mais comuns referem-se à falta de preparo, de estrutura e de seriedade dos franqueados (Bernard, 1993; Schwartz, 1994).

Estes dados não são, de modo algum, suficientes para negar a importância do franchising como estratégia de crescimento e comercialização, mas levantam questões fundamentais que devem ser discutidas, para que o sistema se profissionalize e aperfeiçoe cada vez mais. Decisões estratégicas erradas de franqueadores, diferentes expectativas e visões conflitantes entre franqueadores e franqueados têm sido responsáveis pelo fracasso de alguns empreendimentos de vulto, sobretudo no ramo de fast-food, o que sinaliza a importância de aprofundar as pesquisas sobre as estratégias competitivas e o relacionamento franqueador-franqueado, com suas conseqüências sobre o desempenho da rede de franquia.

A identificação dos fatores de sucesso e fracasso envolvidos nesse tipo de relacionamento, um maior entendimento de como os franqueados das redes percebem e executam as estratégias competitivas preconizadas por seus franqueadores e o monitoramento da satisfação dos franqueados com o relacionamento são cruciais para a contínua melhoria e o sucesso do franchising a longo prazo.

\section{A Relação entre Estratégia e Relacionamento Franqueador-Franqueado}

Com base na tipologia de estratégias de Porter (1980), Bernard (1993) identifica a utilização do franchising como uma diferenciação na estratégia de distribuição dos ramos de comércio especializado e de serviço. Mauro (1994) explica que a decisão de implantar o franchising é apoiada pela avaliação de canais de distribuição e de alternativas de desenvolvimento para o negócio, caracterizando-se, portanto, como decisão estratégica de grande relevância e inserida na tendência mundial de maior integração dos membros do canal de distribuição, com vistas a maximizar os resultados de todos os envolvidos. Mauro (1994) ressalta a importância de a empresa franqueadora ter em mente que seu negócio não é abrir franquias, sendo esta atividade apenas uma estratégia de negócio. O sucesso do negócio principal vai depender do posicionamento estratégico da empresa perante o mercado e a concorrência e da eficaz operacionalização dessas estratégias.

Como, no caso do franchising, as estratégias competitivas, políticas, normas e rotinas formuladas pelo franqueador devem ser disseminadas entre o conjunto 
de franqueados e por estes cumpridas, é de se supor que um adequado nível de relacionamento entre ambas as partes viabilizará esta situação e se refletirá no bom desempenho da rede como um todo, sendo o contrário também verdadeiro. Bernard (1993) ressalta que o processo sinergético entre franqueador e franqueado depende da existência, no franqueador, de fatores mercadológicos, técnicos, financeiros, de recursos humanos e organizacionais, que devem ser por ele utilizados na efetivação do relacionamento.

Na visão de Porter (1980), o relacionamento entre a empresa e outras empresas por ela administradas (caso aplicável ao franchising) é mais uma estratégia competitiva a ser desenvolvida e que influencia seu desempenho, quando combinada às demais estratégias que operacionalizam uma estratégia genérica. Porter (1980) teoriza que dentro de um mesmo segmento de negócio, doravante referido como indústria, a adoção de diferentes estratégias competitivas contribui para o sucesso ou fracasso das empresas; porém, no caso específico do franchising, somente essas estratégias voltadas para o ambiente externo à rede podem não ser suficientes para explicar o desempenho alcançado por toda a rede ou por seus franqueados individualmente. O melhor ou pior relacionamento entre franqueador e franqueado, enquanto resultado de uma estratégia (intencional ou não) do franqueador voltada para seu ambiente interno, pode ser fator relevante para o sucesso ou fracasso do empreendimento.

\section{Formulação do Problema}

Nesse contexto, poder-se-ia hipoteticamente enquadrar o relacionamento entre franqueadores e franqueados dentro de um continuum tal que um extremo se caracterizasse pela adoção, pelo franqueador, de uma visão (e conseqüente ação) puramente competitiva e instrumental do relacionamento com seus franqueados, os quais seriam considerados apenas como fornecedores de capital ou canais de distribuição, enquanto o outro extremo se caracterizasse pela valorização e priorização total do relacionamento, sendo os franqueados vistos como parte integrante da organização e participando ativamente da formulação de estratégias competitivas, numa ampla parceria. Entende-se que, no primeiro caso, a qualidade desse relacionamento seria mínima, enquanto no segundo caso, ela seria máxima. Podem-se prever, assim, diversas combinações possíveis de interação (pontos ao longo do continuum), levando a diferentes níveis de qualidade na relação franqueador-franqueado. Obviamente, no mundo real os extremos não se sustentam ao longo do tempo. Franqueadores que explorem seus franqueados acabarão por perdê-los e dificilmente encontrarão novos parceiros. Por 
outro lado, franqueadores que vejam seus franqueados como a parte mais importante de seu negócio acabam perdendo o foco estratégico e agindo de maneira paternalista, o que, em algum momento, acabará inviabilizando o negócio como um todo.

A questão que se coloca é se o papel desempenhado pelo relacionamento franqueador-franqueado enquanto estratégia competitiva, intencional ou não, voltada para dentro da rede de franquia é tão relevante para o desempenho da rede de franquias e de seus franqueados individualmente quanto o papel das estratégias competitivas que enfocam somente o ambiente externo à rede e, ainda, se é possível obter equilíbrio entre elas. Assim, com base nas dimensões utilizadas por Porter (1980) para a formulação de estratégias competitivas e na metodologia para formação de grupos estratégicos aplicada a um conjunto de redes de franquia em uma dada indústria, formulam-se estes três questionamentos:

. Dentro de determinada indústria, existe diferença significativa entre o desempenho médio de grupos estratégicos formados por franqueados que percebam um enfoque maior de seus respectivos franqueadores com a qualidade do relacionamento franqueador-franqueado (alta qualidade do relacionamento) e o desempenho médio daqueles grupos estratégicos de franqueados que percebem o contrário (média ou baixa qualidade do relacionamento)?

. Se existem diferenças, a qualidade percebida do relacionamento franqueador-franqueado é o fator mais relevante para explicar essa diferença de desempenho?

- Se a qualidade percebida do relacionamento franqueador-franqueado é o fator mais relevante na explicação da diferença de desempenho, que características (variáveis) desse relacionamento são determinantes do desempenho dos grupos estratégicos de franqueados?

Optou-se por focar a atenção da pesquisa para o relacionamento visto pela ótica dos franqueados ou por sua percepção, por ser este grupo mais numeroso e que se encontra, em tese, em posição mais fraca dentro do relacionamento, já que o franqueador detém a marca e o know-how e os custos de término do relacionamento são em geral mais altos para o franqueado. Na Figura 1 é retratada a modelagem geral do problema, já aberta em termos do desempenho dos franqueados versus a qualidade percebida do relacionamento franqueador-franqueado para cada grupo estratégico, formado segundo a metodologia de Porter (1980). Os componentes do modelo relativos ao relacionamento franqueador-franqueado foram caracterizados mediante variáveis observáveis que pudessem ser medidas pela coleta de dados junto aos franqueados. O desempenho dos franqueados foi medido por meio do grau de satisfação expresso por eles mesmos quanto ao seu desempenho geral e quanto ao retorno sobre seu investimento inicial. 


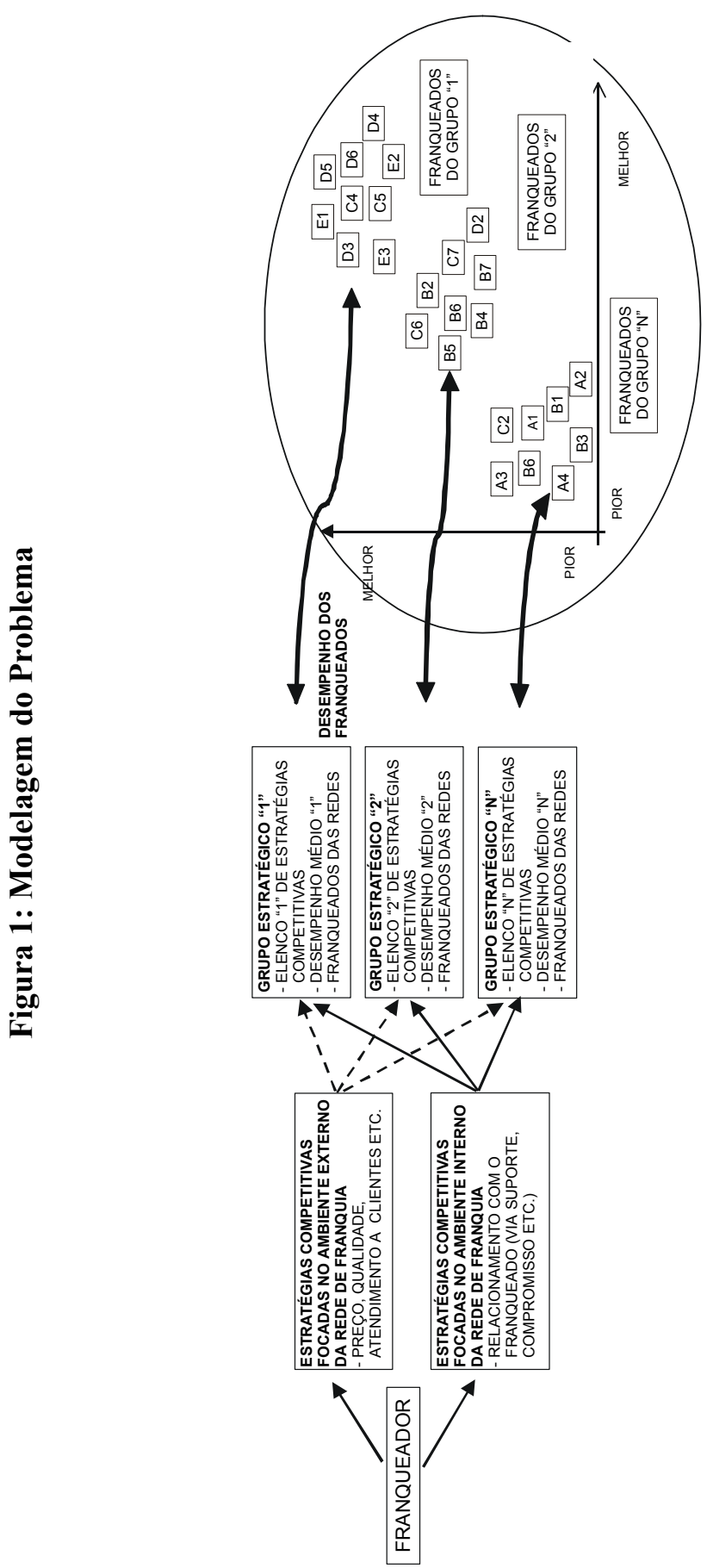




\section{A Pesquisa}

\section{Objetivos da Pesquisa}

. Identificar se a diferença de desempenho médio entre grupos estratégicos de franqueados de uma dada indústria pode ser explicada pela diferença na qualidade do relacionamento franqueador-franqueado percebida por esses mesmos franqueados.

- Identificar que componentes dessa qualidade de relacionamento franqueadorfranqueado são responsáveis pelo melhor ou pior desempenho dos grupos de franqueados dessa indústria.

Durante a realização da pesquisa, foram perseguidos os seguintes objetivos intermediários: a definição de indicadores para a medição do desempenho médio dos franqueados e a definição das variáveis observáveis, que medissem adequadamente a variável latente proposta qualidade do relacionamento entre franqueador e franqueados (abreviada por QRFF), testando-se, a partir da amostra selecionada, se essas variáveis poderiam representar o conceito adequadamente.

\section{A Seleção das Dimensões Estratégicas Competitivas}

Porter (1980) define vantagem competitiva como o resultado da ação de uma empresa ao criar valor para seus compradores (o que eles estão dispostos a pagar) e que ultrapassa o custo de fabricação pela empresa. Para ele, a base fundamental de desempenho acima da média, no longo prazo, é a vantagem competitiva sustentável. Existem para Porter (1980) dois tipos básicos de vantagem competitiva: baixo custo de seus produtos e serviços e sua diferenciação em face da concorrência, determinando os pontos fortes e fracos da empresa. Esses dois tipos básicos de vantagem competitiva, combinados com o escopo de atividades em que a empresa deseja atuar, geram três tipos de estratégias: liderança de custo, diferenciação e enfoque, podendo este se dar no nível de custo ou na diferenciação. Porter (1980) ainda menciona outra estratégia genérica, caracterizada por um meio-termo (stuck in the middle), isto é, o fracasso em desenvolver uma das três estratégias, ficando, assim, em situação desvantajosa em relação à concorrência. As opções de estratégias genéricas das empresas para competir em dada indústria são operacionalizadas por meio do conjunto de estratégias competitivas adotadas. As dimensões das estratégias competitivas citadas por Porter (1980) como representativas das diferentes opções estratégicas das empresas são: especialização, identificação de marcas, política de canal, seleção de 
canal, qualidade do produto, liderança tecnológica, integração vertical, posição de custo, atendimento a clientes, política de preço, grau de alavancagem, relacionamento com a matriz e relacionamento com os países de origem e anfitriões.

Dessa lista foram selecionadas aquelas dimensões estratégicas que melhor se adaptam ao caso do franchising e a uma indústria fragmentada como a do fastfood, procurando-se adaptá-las à realidade vivenciada pelos franqueados, a fim de permitir melhor compreensão de sua parte durante a coleta dos dados. Assim, especialização (sob a forma de variedade da linha de produtos), identificação da marca, qualidade do produto, integração vertical (medida através da quantidade de serviços de apoio oferecidos aos franqueados), posição de custo (despesa operacional), atendimento a clientes, seleção do canal (escolha de seu franqueado) e política de preço foram selecionadas e a elas agregadas uma variável logística crítica em varejo de fast-food: participação do franqueador na definição do ponto. A política de canal está implícita na escolha do franchising como canal de distribuição dos produtos e serviços das redes franqueadoras. Ainda segundo Porter (1980), um grupo estratégico, dentro de determinada indústria, é formado por empresas que estão seguindo uma estratégia idêntica ou semelhante ao longo das dimensões estratégicas. As empresas que compõem um mesmo grupo estratégico apresentam, aproximadamente, a mesma taxa de lucratividade no longo prazo (isto é, desempenhos médios semelhantes), medida em geral pelo retorno sobre o investimento (ROI).

\section{A Seleção das Variáveis de Relacionamento}

\section{Relacionamento em Franchising como parte de uma Estratégia de Marketing}

Segundo Gronroos (1995), a sociedade ocidental já vive dentro de uma economia de serviços, descrita como jogo entre pessoas, onde o gerenciamento dos relacionamentos entre as empresas e seus clientes e mesmo entre os próprios empregados torna-se um fator crítico. Já Bharadwaj, Varadarajan e Fahy (1993), em seu modelo contingencial de vantagem competitiva sustentada em indústrias de serviço, listam como potenciais fontes de vantagem competitiva de uma empresa seus relacionamentos formais e informais. Mauro (1994) vai mais além, ao inserir fornecedores e membros do canal de distribuição dentro desse relacionamento.

Parece mesmo evidente que as definições anteriores englobem também todos os agentes intervenientes no processo de produzir e fazer chegar aos clientes os produtos e serviços desejados: os fornecedores de matérias-primas, produtos 
acabados, equipamentos e os membros do canal de distribuição, que no caso específico do franchising são as empresas franqueadas que compõem a rede do franqueador. Neste processo em particular, o franqueador entra também como fornecedor de serviços, formalizados por contrato ou não, aos franqueados, tais como treinamento, apoio operacional e administrativo, transferência de tecnologia (know-how) e, em se tratando de parceria cuja duração se pretende seja longa, de aspectos mais subjetivos do relacionamento, como credibilidade, ação ética etc.

É senso comum que o franchising é uma associação baseada na cooperação entre indivíduos com o desejo de se tornarem empreendedores, mas que têm aversão ao risco, e empresas sem capital próprio suficiente para se expandirem e que não desejam perder o controle sobre o negócio (Mauro, 1994; Gangana, 1996). Mauro (1994) ressalta que, no caso do franchising, o franqueador exerce não apenas o papel de orientador e controlador, mas também o de parceiro de seu franqueado, obrigando-se a certa divisão de poder e negociação na tomada de decisão, a fim de alcançar o equilíbrio entre cooperação e conflito. O relacionamento entre o franqueador e seu franqueado é baseado numa parceria formalizada em contrato que estipula direitos e obrigações mútuos. Esse relacionamento, porém, não se esgota no cumprimento do contrato; vai muito além, envolvendo contatos interpessoais diários focados na operacionalização e acompanhamento do negócio do franqueado, resolução de problemas comuns e, num plano mais intangível, o compartilhamento de valores e objetivos e aspectos psicológicos e sociais que permeiam a interação das partes. Seltz (1982) adverte, até mesmo, para a mudança ocorrida nos últimos anos no relacionamento entre franqueadores e franqueados bem sucedidos. A estrutura verticalizada, onde o franqueador assumia papel autocrático, do alto do poder hierárquico, vem dando lugar a uma estrutura horizontalizada, onde prevalece o senso de igualdade devido à mútua dependência. Já Gangana (1996) conclui em sua pesquisa que o conceito de marketing de relacionamento é perfeitamente aplicável ao caso do franchising sobretudo na relação franqueador-franqueado, pois esta demandaria grande esforço em todos os estágios do negócio, a fim de garantir o sucesso e a satisfação de ambas as partes. A aplicação prática do modelo de marketing de relacionamento ao caso do franchising seria para Gangana (1996) um dos modos de resolver e mesmo evitar conflitos entre os franqueadores e seus franqueados.

\section{As Variáveis Observáveis do Relacionamento Franqueador- Franqueado}

Quanto à definição de relacionamento franqueador-franqueado, desenvolveuse uma modelagem durante a pesquisa que, sem a pretensão de ser completa, 
procurou incorporar as principais variáveis observáveis envolvidas no relacionamento global franqueador-franqueado e que são amplamente citadas na literatura sobre franchising, marketing de relacionamento e estratégias colaborativas. A literatura sobre o tema é farta na identificação das variáveis que explicitam esse complexo relacionamento. Foram escolhidas cinco variáveis porque elas constituem senso comum entre vários autores, teóricos e pesquisadores. Elas são apresentadas a seguir.

\section{. Transferência de conhecimento (know-how) do franqueador ao franquea-}

do: incluindo manuais de operação; treinamento inicial e contínuo; seminários; supervisão de campo; unidade-piloto; investimento em tecnologias. Citados por Seltz (1982), Cherto (1988), Mendez e Lehnisch (1991), Bernardino (1994), Shane (1996) e Kaner (1997).

- Suporte administrativo-operacional do franqueador ao franqueado: consultoria de campo; auxílio no processo de compras; compras centralizadas; apoio de marketing; apoio logístico; orientação em contabilidade, estoques etc.; rede de informática. Citados por Seltz (1982), Leite (1991), Mendez e Lehnisch (1991), Bernard (1993), Shane (1996) e Kaner (1997).

. Comunicação entre franqueador e franqueado: relatórios sobre desempenho dos franqueados; Conselho de Franqueados; jornais internos; fluxo contínuo de informações para franqueado; ligações telefônicas; conversa informal. Citados por Seltz (1982), Mendez e Lehnisch (1991), Mendelsohn (1994), Barroso (1996), Kaner (1997) e Seideman (1997).

- Confiança inspirada pelo franqueador em seu franqueado: respeito ao contrato; cumprimento de promessas informais; valores éticos do franqueador; tratamento do franqueado perante outros franqueados; transparência nos negócios; negociação de disputas; imagem do franqueador. Citados por Seltz (1982), Mendez e Lehnisch (1991), Leite (1991), Hoffman e Preble (1993), Mauro (1994), Mendelsohn (1994), Gangana (1996), Cox (1996) e Kaner (1997).

. Compromisso do franqueador com o relacionamento: esforços para garantir continuidade da parceria; repasse de ganhos de escala; esforços para evitar conflito e resolver problemas; reconhecimento dos esforços do franqueado; não abertura de concorrência na área do franqueado. Citados por Leite (1991), Sherman (1993), Mauro (1994), Mendelsohn (1994), Bernardino (1994), Blair (1995), Cox (1996), Gangana (1996), Seideman (1997) e Cherto (1998). 


\section{Metodologia}

\section{Formulação de Hipóteses}

Primeiramente, foram geradas as hipóteses a testar. A premissa na qual se basearam as hipóteses a seguir é a de que o desempenho de um franqueado em um negócio de franchising a médio e longo prazo é fortemente influenciado pela adequada aplicação de estratégias competitivas estabelecidas e impostas por seu franqueador. Esta premissa é corroborada por pesquisas recentes (Silva, 1997), que mostram a influência das estratégias competitivas no desempenho das empresas. A pesquisa limitou-se a adotar a classificação de Porter (1980) como explicativa das estratégias competitivas utilizadas pelas empresas e sua metodologia para a formação de grupos estratégicos dentro de uma indústria, por considerá-las satisfatoriamente testadas na prática e amplamente aceitas no meio acadêmico.

A primeira hipótese testada foi a de que a variável latente qualidade do relacionamento franqueador-franqueado (QRFF) pudesse ser representada por variáveis observáveis.

A segunda hipótese estabelecia que, dentro de determinada indústria, existiria diferença significativa entre o desempenho médio de grupos estratégicos formados por franqueados que percebessem um enfoque maior de seus respectivos franqueadores com a qualidade do relacionamento franqueador-franqueado (alta qualidade do relacionamento) e o desempenho médio dos grupos de franqueados que percebessem o contrário (baixa qualidade).

A terceira hipótese foi de que a diferença no desempenho médio dos grupos estratégicos seria tanto maior quanto maior fosse a diferença na qualidade do relacionamento.

A quarta hipótese foi de que, dentre os fatores que afetam a diferença de desempenho entre os grupos estratégicos, a qualidade do relacionamento franqueador-franqueado seria mais relevante.

\section{Seleção do Universo, Amostra e Sujeitos}

Em virtude da grande diversidade de indústrias abrangidas pelo franchising, restringiu-se o estudo a uma determinada indústria que, pelo seu rápido desenvolvimento nos últimos cinco anos e acentuada e dinâmica concorrência e número de negócios de franchising, apresenta-se atraente para este tipo de estudo: 
a indústria do fast-food. Além disso, a escolha do fast-food deveu-se também ao fato de ser esta uma indústria onde o franchising já se encontra implantado há bastante tempo, possuindo, portanto, um grau mínimo de estabilidade, que permite chegar a conclusões mais confiáveis. Finalmente, a limitação do universo da pesquisa a uma só indústria permitiu também chegar a resultados mais homogêneos e de mais fácil interpretação.

Definiu-se o universo da pesquisa como sendo constituído dos negócios franqueados de alimentação fast-food no Brasil com pelo menos um ano de participação na sua rede franqueadora, com o objetivo de garantir a confiabilidade e homogeneidade das respostas, visto que franqueados com menos de um ano nas redes têm expectativas e visões diferentes de desempenho e relacionamento daquelas dos franqueados mais antigos e podem ter mais dificuldades em reconhecer as estratégias praticadas por seus franqueadores. Reconhece-se que este limite ainda não é o ideal, mas dada a estrutura relativamente recente do franchising no Brasil, optou-se por ele para não reduzir demais a amostra.

Dentro desse universo, definiu-se a população de trabalho, isto é, aquela da qual os elementos da amostra podem ser retirados (Zikmund, 1994), como sendo composta pelas lojas franqueadas, cujas redes franqueadoras estivessem utilizando o franchising há pelo menos três anos (desde 1995), parcial ou totalmente formatado. Entende-se que redes franqueadoras muito recentes ainda estejam atravessando uma fase de consolidação, o que pode levar a objetivos distintos das redes já consolidadas e a graus muito diferentes de desempenho dos seus franqueados e de relacionamento entre ambos. Sendo essa situação potencialmente geradora de distorções na análise, optou-se por evitá-la. Foram convidadas a participar da pesquisa as redes franqueadoras da população de trabalho identificada, com garantia de retorno dos resultados bem como o do sigilo das informações obtidas. Doze redes aceitaram participar da pesquisa. Os sujeitos da pesquisa foram identificados como sendo os sócios responsáveis pela operação das lojas franqueadas. Os questionários deveriam ser preenchidos somente por eles. Ao final, chegou-se a 369 negócios franqueados para os quais deveriam ser enviados questionários.

\section{Coleta e Tratamento dos Dados}

Os dados foram coletados por meio de um questionário pré-testado enviado aos franqueados da amostra, planejada pelos próprios franqueadores, mas retornado diretamente ao pesquisador pelo correio, a fim garantir o sigilo das respostas. O período avaliado pelo questionário foi de julho de 1995 a junho de 1998 (ou desde quando o franqueado tenha entrado na rede até junho de 1998). O questionário foi dividido em 4 partes: 
. 1ªrte: 5 questões abertas com dados gerais do franqueado.

. $2^{\mathrm{a}}$ Parte: 4 questões de múltipla escolha para medição da satisfação do franqueado com seu desempenho dentro do período de referência da pesquisa, solicitando-se uma comparação com a concorrência. Utilizou-se uma escala ordinal do tipo Likert de 5 pontos: Muito Insatisfeito (valor 1), Insatisfeito (valor 2), Nem satisfeito nem insatisfeito (valor 3), Satisfeito (valor 4) e Muito Satisfeito (valor 5). Optou-se pelo uso de indicadores qualitativos de caráter subjetivo, dada a dificuldade que se tem nesse setor de se obter com confiabilidade o indicador de retorno sobre investimento. Foram medidas duas variáveis: desempenho geral (DESEMPGE) e retorno do investimento inicial (ROI). Essa prática tem sido utilizada com bastante eficácia em pesquisas na área de marketing (Silva, 1997).

. 3 Parte: 8 questões de múltipla escolha para medição da percepção do franqueado sobre as estratégias competitivas praticadas por seus franqueadores em face da concorrência no mesmo período, segundo o modelo de Porter (1980) adaptado à realidade do franchising de varejo. Utilizou-se a mesma escala tipo Likert de 5 pontos, só que comparando-se as estratégias com a concorrência.

4 Parte: 6 questões de múltipla escolha para medição da satisfação do franqueado com o relacionamento (parceria) dentro do período de referência da pesquisa. Além das 5 variáveis observáveis de relacionamento citadas anteriormente, mediu-se a satisfação global com o relacionamento, a fim de permitir uma posterior regressão e verificar se existia correlação significativa entre uma avaliação global e as 5 variáveis tomadas em conjunto. Utilizou-se a mesma escala tipo Likert de 5 pontos com as mesmas alternativas da $2^{a}$ parte.

A amostra real com a qual se trabalhou foi composta pelos 152 negócios franqueados, com pelo menos um ano de rede, que responderam ao questionário até a data limite de $05 / 10 / 98$, isto é, $41,2 \%$ da amostra planejada. Dos 152 respondentes, 103 eram donos de apenas uma loja franqueada $(67,8 \%)$ e quase $50 \%$ se situavam no Estado de São Paulo. Os procedimentos estatísticos utilizados na pesquisa encontram-se disponíveis em arquivos do software SPSS versão 7.5. Para cada questão do questionário foi criada uma variável no SPSS. O tratamento e a análise dos dados qualitativos foram eminentemente quantitativos. Fizeram-se análises da normalidade das variáveis medidas visando a eliminar da pesquisa aquelas variáveis que tinham distribuição acentuadamente não normal. Foi eliminada a variável SATISCLI, que media a satisfação dos clientes com os serviços do franqueado. As variáveis utilizadas são mostradas na Tabela 1. 
Tabela 1: Variáveis Utilizadas na Pesquisa

\begin{tabular}{|c|c|c|c|c|c|}
\hline $\begin{array}{c}\text { Avaliações feitas pelos } \\
\text { franqueados }\end{array}$ & $\begin{array}{l}\text { Código da } \\
\text { Variável }\end{array}$ & $\begin{array}{c}\text { Casos } \\
\text { Válidos }\end{array}$ & Média & $\begin{array}{l}\text { Desvio } \\
\text { Padrão }\end{array}$ & $\begin{array}{l}\text { Teste t para } \\
\text { média }=3,0\end{array}$ \\
\hline Variáveis de Desempenho & & & & & signif. $(0,05)$ \\
\hline $\begin{array}{l}\text { Satisfação com o desempenho } \\
\text { geral }\end{array}$ & DESEMPGE & 152 & 3,184 & 1,064 & 0,034 \\
\hline $\begin{array}{l}\text { Satisfação com o retorno } \\
\text { financeiro }\end{array}$ & ROI & 151 & 2,722 & 1,223 & 0,006 \\
\hline \multicolumn{6}{|l|}{$\begin{array}{l}\text { Variáveis de } \\
\text { Relacionamento }\end{array}$} \\
\hline $\begin{array}{l}\text { Nível de confiança no } \\
\text { franqueador }\end{array}$ & CONFIANC & 152 & 3,041 & 1,031 & 0,000 \\
\hline $\begin{array}{l}\text { Satisfação c/ transferência de } \\
\text { know-how }\end{array}$ & KNOWHOW & 152 & 3,276 & 1,062 & 0,002 \\
\hline $\begin{array}{l}\text { Satisfação com suporte } \\
\text { operacional }\end{array}$ & SUPORTE & 152 & 2,980 & 1,113 & 0,827 \\
\hline $\begin{array}{l}\text { Satisfação com o } \\
\text { compromisso }\end{array}$ & COMPROMI & 152 & 2,868 & 1,149 & 0,160 \\
\hline Satisfação com comunicação & COMUNICA & 152 & 2,836 & 1,159 & 0,082 \\
\hline $\begin{array}{l}\text { Satisfação com o } \\
\text { relacionamento global }\end{array}$ & RELGLOBA & 152 & 3,362 & 1,077 & 0,000 \\
\hline \multicolumn{6}{|l|}{$\begin{array}{l}\text { Variáveis de Estratégia } \\
\text { Externa frente à } \\
\text { Concorrência }\end{array}$} \\
\hline $\begin{array}{l}\text { Política de preços do } \\
\text { franqueador }\end{array}$ & PREÇOS & 150 & 2,827 & 0,918 & 0,022 \\
\hline Despesas operacionais da rede & DESPESA & 143 & 2,692 & 0,890 & 0,000 \\
\hline Força da marca & MARCA & 151 & 2,106 & 1,138 & 0,000 \\
\hline $\begin{array}{l}\text { Variedade dos produtos e } \\
\text { serviços }\end{array}$ & VARIEDAD & 151 & 3,192 & 1,024 & 0,023 \\
\hline $\begin{array}{l}\text { Qualidade dos produtos e } \\
\text { serviços }\end{array}$ & QUALIDAD & 151 & 4,046 & 0,686 & 0,000 \\
\hline \multicolumn{6}{|l|}{$\begin{array}{l}\text { Outras Variáveis de } \\
\text { Estratégia Externa }\end{array}$} \\
\hline $\begin{array}{l}\text { Grau de participação do } \\
\text { franqueador na seleção do } \\
\text { ponto }\end{array}$ & PARTPONT & 152 & 3,355 & 1,215 & 0,000 \\
\hline $\begin{array}{l}\text { Quantidade de serviços } \\
\text { oferecidos ao franqueado }\end{array}$ & PARTAPOI & 152 & 3,309 & 1,278 & 0,003 \\
\hline $\begin{array}{l}\text { Profissionalismo na seleção } \\
\text { dos franqueados }\end{array}$ & PROFISSI & 151 & 3,046 & 0,962 & 0,554 \\
\hline
\end{tabular}

Formou-se, então, um espaço denominado estratégia-relacionamento, com as 8 variáveis de estratégia competitiva externa à rede e as 5 variáveis que mediam as estratégias internas à rede (relacionamento franqueador-franqueado). Esse 
espaço foi reduzido e normalizado por meio de uma análise de fatores com rotação Varimax. Foram, então, formados os grupos estratégicos que reúnem os franqueados da amostra em clusters, por meio da aplicação de uma análise de clusters hierárquica, seguida de uma análise de clusters $k$-means, utilizando-se como critério balizador os desempenhos dos franqueados, medidos pelas variáveis ROI e DESEMPGE, dado que Porter (1980) teoriza que empresas pertencentes a um mesmo grupo estratégico obtêm desempenhos aproximadamente iguais.

A análise de clusters foi aplicada a duas situações:

. $1^{\text {a }}$ situação - espaço estratégia-relacionamento: pela análise de fatores.

- $2^{\mathrm{a}}$ situação - espaço estratégia-relacionamento: pela análise das 13 variáveis, a fim de verificar se a análise dos fatores não comprometia o resultado da pesquisa.

Formados os grupos estratégicos, verificou-se, por meio de uma combinação de MANOVA e ANOVA com teste post-hoc de Bonferroni, se havia diferença significativa entre as médias das variáveis ROI e DESEMPGE de cada grupo estratégico, considerando-se uma probabilidade de 5\% de cometer um erro do tipo I (rejeitar a hipótese nula de que as médias são iguais quando ela é verdadeira). O teste de Bonferroni permitiu comparar as médias de ROI e DESEMPGE entre os grupos estratégicos, par a par, podendo-se a partir daí estabelecer quais os grupos estratégicos de melhor desempenho. Procurou-se verificar se os grupos de melhor desempenho eram aqueles para os quais os franqueados percebiam a prática por parte de seus respectivos franqueadores de uma estratégia onde prevalecia a ênfase na qualidade do relacionamento franqueador-franqueado (maior QRFF), medida pela satisfação do franqueado.

\section{Apresentação e AnÁlise dos Resultados}

A aplicação da análise de fatores reduziu o espaço estratégia-relacionamento inicial a 4 fatores normalizados, sendo que um deles (o fator 1) agrupava as 5 variáveis de relacionamento: COMPROMI, COMUNICA, CONFIANC, KNOWHOW e SUPORTE, cada qual com cargas elevadas de fatores (maiores que 0,50 em valores absolutos), fornecendo forte indício de que essas variáveis observáveis poderiam ser utilizadas como parâmetros de medição da satisfação dos franqueados em relação ao relacionamento com seu franqueador, ou seja, uma medida da qualidade desse relacionamento. Isso foi confirmado pela análise de regressão múltipla, que indicou forte correlação entre a variável 
RELGLOBA (avaliação global do relacionamento) e essas variáveis, tendo-se encontrado alto coeficiente de determinação múltipla $\mathbf{R}^{2}$ ajustado $(0,778)$, que mede a percentagem em RELGLOBA, que pode ser explicada pela variação em todas as 5 variáveis independentes. $\mathrm{O}$ teste de $\mathrm{F}$ para $\mathbf{R}^{2}$ foi significante com zeros até a terceira casa decimal, indicando que o modelo é relevante para a análise; no entanto a variável SUPORTE não passou no teste t a 5\%, cuja hipótese nula era de que seu coeficiente beta fosse nulo. Considerou-se, assim, nula a influência desta variável sobre RELGLOBA. Verificou-se, ao final, que o fator 1 poderia perfeitamente representar a variável latente qualidade do relacionamento franqueador-franqueado (QRFF), o que comprovou a primeira hipótese desta pesquisa e atendeu ao segundo objetivo. A Tabela 2 mostra o novo espaço reduzido.

\section{Tabela 2: Espaço Reduzido Estratégia-Relacionamento com as Novas Variáveis (Fatores)}

\begin{tabular}{|c|l|l|l|}
\hline Fator & \multicolumn{1}{|c|}{$\begin{array}{c}\text { Fatores } \\
\text { Normalizados }\end{array}$} & \multicolumn{1}{|c|}{ Variáveis Agrupadas } & \multicolumn{1}{|c|}{ Estratégias Representadas } \\
\hline 1 & ZQRFF & $\begin{array}{l}\text { COMPROMI, COMUNICA, } \\
\text { CONFIANC, KNOWHOW, } \\
\text { SUPORTE }\end{array}$ & $\begin{array}{l}\text { Qualidade do relacionamento } \\
\text { entre franqueador e seus } \\
\text { franqueados }\end{array}$ \\
\hline 2 & ZCUSTO & MARCA, DESPESA, PREÇOS & $\begin{array}{l}\text { Ênfase em custos (e preços) mais } \\
\text { baixos que a concorrência }\end{array}$ \\
\hline 3 & ZLOGISTI & $\begin{array}{l}\text { PARTAPOI, PARTPONT, } \\
\text { PROFISSI }\end{array}$ & $\begin{array}{l}\text { Suporte logístico oferecido aos } \\
\text { franqueados }\end{array}$ \\
\hline 4 & ZCLIENTE & QUALIDAD, VARIEDAD & Serviço prestado aos clientes \\
\hline
\end{tabular}

Cada cluster formado pela análise de clusters é uma combinação significativamente diferente desses 4 fatores (estratégias). A análise de cluster $k$-means no espaço reduzido e normalizado estratégia-relacionamento, variando o número de clusters informados entre 3 e 8, indicou a configuração de 5 clusters como a de melhor poder explanatório. Esta configuração foi salva como nova variável (NCLEST5). A Tabela 3 apresenta os 5 grupos estratégicos formados. Só o grupo 1 não apresentou predomínio de qualquer estratégia. Já no espaço completo, a análise de cluster levou à formação de 6 grupos estratégicos, sendo esta configuração salva também como nova variável (ZCLEST6), e mostrada na Tabela 5.

Ao aplicar-se o procedimento de MANOVA às 4 variáveis normalizadas para o fator fixo NCLEST5, a transformada F da estatística $\mathrm{T}^{2}$ de Hotelling apresentou valor igual a 36,829 com nível de significância igual a 0,000. Para o fator fixo ZCLEST6, o teste F para as 13 variáveis normalizadas do espaço completo resultou em um valor de F igual a 14,227 com significância igual a 0,000. Esses 
valores confirmaram, nos dois espaços, que os vetores que representam os centróides de cada grupo estratégico são realmente diferentes entre si.

\section{Tabela 3: Configurações de Grupos Estratégicos no Espaço Reduzido (NCLEST 5)}

\begin{tabular}{|c|c|l|}
\hline Grupos & Franqueados & \multicolumn{1}{|c|}{ Característica dos Grupos Estratégicos no Espaço Reduzido } \\
\hline 1 & 29 & $\begin{array}{l}\text { Sem estratégia definida } \\
\text { Atuação fraca em todas as 4 estratégias, principalmente custos }\end{array}$ \\
\hline 2 & 33 & $\begin{array}{l}\text { Direcionado para Custos e Preços Baixos } \\
\text { Marca e qualidade de relacionamento fracas e logística fraca }\end{array}$ \\
\hline 3 & 43 & $\begin{array}{l}\text { Direcionado para Alta Qualidade de Relacionamento } \\
\text { Logística acima da média, serviço a clientes, custo/preço na média }\end{array}$ \\
\hline 4 & 23 & $\begin{array}{l}\text { Direcionado para Serviço ao Cliente } \\
\text { Fraca atuação nas demais estratégias, sobretudo no relacionamento }\end{array}$ \\
\hline 5 & 24 & $\begin{array}{l}\text { Direcionado para Logística da Rede } \\
\text { Qualidade de relacionamento muito fraca e custos e preços médios }\end{array}$ \\
\hline
\end{tabular}

Testou-se, então, no espaço reduzido estratégia-relacionamento, se havia diferença significante entre os grupos formados, por meio das médias das variáveis de desempenho ROI e DESEMPGE separadamente. Aplicando-se o procedimento de ANOVA com teste post-hoc de Bonferroni, tendo como fator fixo a variável NCLEST5 (assumindo níveis 1 a 5), observou-se que em termos de retorno financeiro sobre o investimento (ROI), o grupo 3 obteve média maior que os demais grupos $(3,40)$. Os franqueados desse grupo, em média, tenderam à satisfação com relação a seu desempenho financeiro. Já o grupo 1 foi o de pior desempenho, com média de 2,10, o que colocou seus franqueados como praticamente insatisfeitos. Foi testado e constatado que a diferença da média de ROI (satisfação com retorno financeiro) entre o grupo 3 e os demais grupos é sempre positiva, sendo que em relação aos grupos 1, 2 e 5 essa diferença mostrou-se significante a 5\%. Em outras palavras, a probabilidade de se considerar a média de ROI para o grupo 3 maior que as médias de 1, 2 e 5, quando na verdade ela não é (risco do tipo I), é quase nula (significância do teste variando entre 0,000 e 0,004). Assim, pôde-se afirmar com segurança que o desempenho do grupo 3, aquele centrado em alta qualidade do relacionamento franqueador-franqueado, era melhor que os demais, com exceção do grupo 4 para o qual a diferença ligeiramente positiva entre as médias favorável ao grupo $3(0,19)$ não foi confirmada pelo teste, não tendo sido possível rejeitar a hipótese nula de que as médias eram iguais. O mesmo ocorreu quando se comparou o ROI dos grupos 1, 2 e 5 entre si. Este resultado é importante, pois o grupo estratégico 3 é aquele cuja combinação de estratégias competitivas se baseia mais fortemente na qualidade 
do relacionamento franqueador-franqueado. Estas conclusões estão resumidas na Tabela 4.

\section{Tabela 4: Interpretação dos Resultados nos Grupos Estratégicos do Espaço Reduzido}

\begin{tabular}{|l|c|l|l|}
\hline \multicolumn{1}{|c|}{ Resultado para ROI } & Grupos & \multicolumn{1}{|c|}{ Estratégia Principal } & \multicolumn{1}{c|}{ Avaliação e Média } \\
\hline Melhor retorno financeiro & 3 & Ênfase na alta QRFF & Satisfeito $(3,40)$ \\
sobre o investimento & 4 & Ênfase no serviço ao cliente & Satisfeito $(3,22)$ \\
\hline Pior retorno financeiro & 5 & Ênfase na logística da rede & Insatisfeito $(2,38)$ \\
sobre o investimento & 2 & Ênfase em custo/preço baixo & Insatisfeito $(2,30)$ \\
& 1 & Sem estratégia definida & Insatisfeito $(2,10)$ \\
\hline Resultado p/ DESEMPGE & Grupos & \multicolumn{1}{c|}{ Estratégia Principal } & Avaliação e Média \\
\hline \multirow{2}{*}{ Melhor desempenho geral } & 3 & Ênfase na QRFF & Satisfeito (3,70) \\
& 4 & Ênfase no serviço ao cliente & Satisfeito $(3,30)$ \\
\hline \multirow{3}{*}{ Pior desempenho geral } & 1 & Sem estratégia definida & Insatisfeito $(2,93)$ \\
& 2 & Ênfase em custo/preço baixo & Insatisfeito $(2,91)$ \\
& 5 & Enfase em logística da rede & Insatisfeito $(2,83)$ \\
\hline
\end{tabular}

Quanto à satisfação com o desempenho geral (DESEMPGE), o grupo 3 manteve média maior que os demais grupos $(3,70)$. Os franqueados desse grupo inclinaram-se, em média, fortemente à satisfação. Mas, agora, foi o grupo 5 o de pior média $(2,83)$, o que classifica seus franqueados como nem satisfeitos nem insatisfeitos. Percebe-se que apesar das variações na ordenação dos desempenhos dos grupos conforme a variável de desempenho medida, os grupos 3 e 4 apresentaram consistentemente os dois melhores resultados, nesta ordem. $\mathrm{O}$ teste de Bonferroni mostrou que a diferença da média de desempenho geral (DESEMPGE) entre o grupo 3 e os demais grupos era sempre positiva, sendo que em relação aos grupos 1,2 e 5 essa diferença mostrou-se significante a 5\%, com probabilidade mínima de cometer-se erro do tipo I para DESEMPGE (significância do teste variando entre 0,01 e 0,02 ). Novamente, o aparente melhor desempenho do grupo 3 em relação ao grupo 4 não pôde ser comprovado estatisticamente, assim como não se pôde diferenciar o desempenho dos grupos 1,2 e 5 entre si.

Aplicou-se o mesmo procedimento de ANOVA com teste post-hoc de Bonferroni ao espaço completo (cujos grupos formados e suas estratégias são mostrados na Tabela 5) e tendo como fator fixo a variável ZCLEST6 (assumindo os níveis 1 a 6). Mais uma vez, comprovou-se que, para a satisfação com o retorno financeiro sobre o investimento (ROI), o grupo que representa a estratégia de alta qualidade do relacionamento (coincidentemente, aqui representado novamente pelo grupo 3 ) obteve média maior que os demais grupos $(3,47)$. Os fran- 
queados desse grupo tendem, em média, levemente à satisfação com relação a seu retorno financeiro.

\section{Tabela 5: Configurações de Grupos Estratégicos no Espaço Completo (NCLEST6)}

\begin{tabular}{|c|c|l|}
\hline Grupos & Franqueados & \multicolumn{1}{|c|}{ Característica dos Grupos Estratégicos no Espaço Completo } \\
\hline 1 & 22 & $\begin{array}{l}\text { Direcionado à marca e logística fortes } \\
\text { Qualidade de relacionamento média, custo e preço elevados }\end{array}$ \\
\hline 2 & 36 & $\begin{array}{l}\text { Direcionado para custos e preços baixos } \\
\text { Marca/qualidade relacionamento médias e logística muito fraca }\end{array}$ \\
\hline 3 & 35 & $\begin{array}{l}\text { Direcionado para alta qualidade de relacionamento } \\
\text { Logística e serviço a clientes médios, custo/preço tendem a altos }\end{array}$ \\
\hline 4 & 14 & $\begin{array}{l}\text { Sem estratégia definida } \\
\text { Atuação fraca em quase todas as estratégias }\end{array}$ \\
\hline 5 & 13 & $\begin{array}{l}\text { Direcionado para a marca forte } \\
\text { Mas com fraca atuação nas demais estratégias, principalmente custos e } \\
\text { relacionamento com franqueados }\end{array}$ \\
\hline 6 & 32 & $\begin{array}{l}\text { Direcionado para logística (principalmente ponto) } \\
\text { Fraca atuação nas demais estratégias, inclusive no relacionamento }\end{array}$ \\
\hline
\end{tabular}

Já o grupo 4 deste espaço, representando os franqueados que não perceberam qualquer direcionamento estratégico de seus franqueadores, foi o de pior desempenho, com média 2,07 (franqueados insatisfeitos). Apesar da numeração do grupo no espaço completo ser diferente em comparação com o espaço reduzido, as características do pior grupo em termos de ROI são as mesmas: sem definição estratégica. Quanto à satisfação com seu desempenho geral (DESEMPGE), o grupo 3 manteve média maior que os demais grupos $(3,80)$. $O$ grupo 4 continuou sendo o de pior média $(2,36)$, tendendo seus franqueados fortemente à insatisfação. Comprovou-se, também, no espaço completo estratégia-relacionamento, que o grupo de estratégia direcionada para a alta qualidade do relacionamento franqueador-franqueado apresentou consistentemente o melhor resultado. A Tabela 6 resume esses resultados.

Verificou-se, assim, que os resultados nos dois espaços levaram à mesma conclusão geral de que o grupo estratégico, cujos franqueados perceberam a alta qualidade do relacionamento franqueador-franqueado, como a estratégia principal do franqueador, também foi o que estava, na média, mais satisfeito com seu desempenho geral e retorno financeiro sobre seu investimento, se comparado aos outros grupos estratégicos formados e que não tiveram a mesma percepção. Assim, a segunda hipótese desta pesquisa, que visava a explicitar esta relação, foi comprovada. 


\section{Tabela 6: Resultados da Comparação dos Grupos Estratégicos para o Espaço Completo}

\begin{tabular}{|l|c|l|l|}
\hline \multicolumn{1}{|c|}{ Resultado para ROI } & Grupos & \multicolumn{1}{|c|}{ Estratégia Principal } & \multicolumn{1}{c|}{ Avaliação e Média } \\
\hline Melhor retorno financeiro & 3 & Ênfase na QRFF & Satisfeito $(3,47)$ \\
sobre o investimento & 1 & Ênfase na marca e logística & Indefinido (2,73) \\
& 2 & Ênfase em custo/preço baixo & Indefinido $(2,67)$ \\
\hline Pior retorno financeiro & 6 & Ênfase em logística da rede & Indefinido $(2,53)$ \\
sobre o investimento & 5 & Ênfase na marca & Insatisfeito $(2,08)$ \\
& 4 & Sem estratégia definida & Insatisfeito $(2,07)$ \\
\hline Resultado p/ DESEMPGE & Grupos & \multicolumn{1}{|c|}{ Estratégia Principal } & Avaliação e Média \\
\hline \multirow{2}{*}{ Melhor desempenho geral } & 3 & Ênfase na QRFF & Satisfeito $(3,80)$ \\
& 2 & Ênfase em custo/preço baixo & Indefinido $(3,36)$ \\
& 1 & Ênfase na marca e logística & Indefinido $(3,09)$ \\
\hline \multirow{3}{*}{ Pior desempenho geral } & 5 & Ênfase na marca & Indefinido $(3,00)$ \\
& 6 & Ênfase em logística da rede & Insatisfeito $(2,81)$ \\
& 4 & Sem estratégia definida & Insatisfeito $(2,36)$ \\
\hline
\end{tabular}

Quanto à quarta hipótese, de que dentre os diferentes fatores que afetam a diferença de desempenho entre os grupos estratégicos, a qualidade do relacionamento franqueador-franqueado fosse a mais relevante, foi verificado pela análise de clusters, nos dois espaços, que o grupo de melhor desempenho (grupo 3 nos dois casos) apresentou direcionamento estratégico, percebido pelos franqueados, para a alta qualidade do relacionamento, tendo sido esta variável estratégica claramente aquela de maior peso na definição do centróide do grupo 3, nos dois espaços. No entanto, tal resultado deve ser analisado com a ressalva de que a qualidade do relacionamento franqueador-franqueado (QRFF) não foi a única estratégia em ação no grupo de melhor desempenho, nos dois casos considerados.

Para comprovar a terceira hipótese de que a diferença no desempenho médio dos grupos estratégicos seria tanto melhor quanto maior fosse a diferença na qualidade do relacionamento, aplicou-se o procedimento de ANOVA com Bonferroni à variável normalizada ZQRFF para os 5 grupos do espaço reduzido, comparando-se o resultado com aqueles obtidos para as variáveis ROI e DESEMPGE. A diferença das médias de ZQRFF entre o grupo 3 e os demais grupos, par a par, não permitiu chegar a uma conclusão sobre esta relação causal, o que pode ser explicado pelo fato de as estratégias prevalentes nos grupos 1,2, 4 e 5 estarem interferindo em seu desempenho muito mais que a qualidade do relacionamento. Em verdade, tal comparação só seria inteiramente válida, se fosse feita entre grupos estratégicos que utilizassem a qualidade do relacionamento (na percepção de seus franqueados) como sua estratégia principal ou se fosse feita entre os subgrupos de franqueados dentro de um mesmo grupo estratégico. Assim sendo, não foi possível comprovar a terceira hipótese da pesquisa. 


\section{CONCLUSÕES}

Como o universo retratado nessa pesquisa se limita à indústria de fast-food, devem-se evitar generalizações das conclusões para todo o sistema de franchising no país. A discussão sobre a adoção de estratégias cooperativas como complemento às estratégias competitivas é um tema muito atual e que começa a ganhar espaço no meio acadêmico. Entende-se que o franchising seja uma opção bem sucedida de formatação de um negócio na qual as duas visões acima citadas podem e devem interagir. Finalmente, espera-se que este estudo tenha conseguido evidenciar a importância do papel do relacionamento franqueador-franqueado como fator de vantagem competitiva neste tipo de negócio, bem como sinalizar a necessidade de aprofundar a discussão sobre a harmonização dos interesses de franqueadores e franqueados.

\section{REFERENCIAS BibLIOGRÁFICAS}

BARROSO, L. F.

Um conselho em questão. O Globo, Rio de Janeiro, 25 ago. 1996.

BERNARD, D. A.

Franchising : avalie este investimento. São Paulo : Editora Atlas, 1993.

BERNARDINO, E.

A franquia é uma via de duas mãos. Exame, 17 ago. 1994, p. 134.

BHARADWAJ, S.;

VARADARAJAN, P. R.;

FAHY J.

Sustainable competitive advantage in service industries : a conceptual model and research propositions. Journal of Marketing, v. 57, p. 83-89, Oct. 1993.

BLAIR, A.

Winning buyers can be winning sellers. Franchising World, p. 40, Sept./Oct. 1995.

CHERTO, M.

Superando conflitos. Pequenas Empresas Grandes Negócios, jul. 1998. n. 114, p. 162.

COX, K. C.

Relationship management orientation and relationship marketing success (franchising). Texas, 1996. Thesis (Doctoral) - Texas Tech University. 
GANGANA, M. G.

Uma análise descritiva do marketing de relacionamento na relação entre franqueado $e$ franqueador : a percepção do franqueado. Rio de Janeiro, 1996. Dissertação (Mestrado) Pontifícia Universidade Católica.

\section{GRONROOS, C.}

Marketing : gerenciamento de serviços. Rio de Janeiro : Campus, 1995.

HOFFMAN, R.;

PREBLE, J. F.

Franchising into the twenty-first century. Business Horizon, p. 35-43, Nov./Dec. 1993.

KANER, L. A. B.

Franchising : fatores críticos de sucesso no ramo de fast-food. Rio de Janeiro, 1997. Dissertação (Mestrado em Administração) Instituto de Pós-Graduação e Pesquisa em Administração, Universidade Federal do Rio de Janeiro.

LEITE, R. C.

Franchising na criação de novos negócios. 2. ed. São Paulo : Atlas, 1991.

MAURO, P. C.

Guia do franqueador : como crescer através do franchising. São Paulo : Nobel, 1994.
MENDELSOHN, M.

A essência do franchising. São Paulo : Difusão Educação e Cultura, 1994.

MENDEZ, M.;

LEHNISCH, J. P.

Como fazer da franquia um bom negócio. São Paulo : Nobel, 1991.

PORTER, M. E.

Competitive strategy. New York : Free Press, 1980.

PROENÇA, M. C.

Análise crítica do sistema de franquias no Brasil. São Paulo, 1997. Tese (Doutorado) - Universidade de São Paulo.

SCHWARTZ, J. C.

Franchising : o que é, como funciona. Brasília : SEBRAE, 1994.

SEIDEMAN, T.

Franchising in the ' $90 \mathrm{~s}$. Franchising World, p. 11-14, May/June 1997.

SELTZ, D. D.

The complete handbook of franchising. Reading, MA : Addison-Wesley, 1982.

SHANE, S.

Franchising : o caminho das pedras. São Paulo : Cherto, 1996. 
SHERMAN, A. J.

The franchising handbook. São

Paulo : Cherto, 1993.

SILVA, J. F. DA.

Desempenho de indústrias : impacto das estratégias competitivas e colaborativas. Rio de Ja- neiro, 1997. Tese (Doutorado em Engenharia Industrial) - Departamento de Engenharia Industrial, Pontifícia Universidade Católica.

ZIKMUND, W. G.

Exploring marketing research. 5. ed. Orlando : The Dryden Press, 1994. 